\title{
IRREVERSIBLE INVESTMENTS AND REGULATORY RISK
}

\author{
PAOLO M. PANTEGHINI \\ CARLO SCARPA
}

CESiFo Working PAPER No. 934

CATEGORY 1: PUBLIC FinANCE

APRIL 2003

An electronic version of the paper may be downloaded

- from the SSRN website:

www.SSRN.com

- from the CESifo website: www.CESifo.de 


\title{
IRREVERSIBLE INVESTMENTS AND REGULATORY RISK
}

\begin{abstract}
This paper addresses the issue of how regulatory constraints affect firm's investment choices when the firm has an option to delay investment. The RPI-x rule is compared to a profit sharing rule, which increases the $x$ factor in case profits go beyond a given level. It is shown that a pure price cap and profit sharing are identical in their impact on investment choices: the change in the option value that we have with a profit sharing regime exactly compensates the change in the "direct" profitability of investment. Regulatory risk - breaching of the regulatory contract - may or may not affect negatively investment decisions. Even if a distortion exists, we show that this distortion is the same, even if a pure price cap could be considered riskier than a profit sharing rule.
\end{abstract}

JEL Code: L51, D92, G31.

Keywords: regulation, investment, RPI-x, profit sharing.

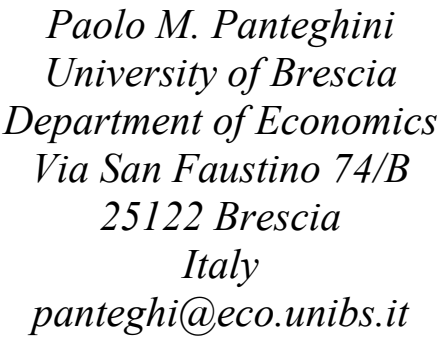

\author{
Carlo Scarpa \\ University of Brescia \\ Department of Economics \\ Via San Faustino 74/B \\ 25122 Brescia \\ Italy \\ cscarpa@eco.unibs.it
}

We would like to thank Giacomo Calzolari, Vesa Kanniainen, Pia Koskenoja, Michele Moretto and participants to seminars at the Universities of Bologna, Helsinki and Padova, at CESifo in Munich and at the RES Conference in Warwick for comments on earlier drafts. 


\section{Introduction}

The theoretical literature and the practical experience on regulated industries try to identify the optimal price scheme, able to strike a balance between the pursuit of allocative efficiency (keeping prices in line with marginal costs), the need to provide an incentive to invest (which is sometimes referred to as "dynamic" efficiency) and the political necessity to take particular care of consumer's welfare (sometimes called "distributional" efficiency). While there is a general tendency to shift from a regulation of the rate of return to a scheme which looks for "efficient" prices, there is little agreement on the optimal pricing scheme. A price cap such as the by now traditional $R P I-x$ seems to provide a reasonable compromise, in that real prices decrease over time while the regulated firm seems to have appropriate incentives to invest ${ }^{1}$.

However, we know from the UK experience that an RPI $-x$ scheme tends to leave the firm large profits. This means that regulators may be subject to considerable political pressures to raise their prices even before the scheduled time (the price review). This has happened for instance in 1995, when the UK electricity regulator - realising that its previous intervention on prices had been too mild - intervened on prices well before the price review, which was due in 1999. Other times, the same type of concern has lead to direct political interventions. This happened for instance when a "windfall tax" on profits was introduced in Britain with the 1997 budget, affecting 33 privatised utilities, whose profits had been considered excessively high.

These possibilities entail a specific type of policy uncertainty for utilities, sometimes called "regulatory risk". The effect of this risk is documented, for instance, by Buckland and Fraser (2001), who indicate that it reverberates into the cost of capital of regulated utilities. As a possible remedy to this problem, an alternative called "sliding scale" (or, less cryptically, "profit sharing") has been considered ${ }^{2}$. According to this scheme, if the firm's profits

\footnotetext{
${ }^{1}$ The idea is that for long periods of time (regulatory periods, which end with a price review), the regulated price should increase at a rate equal to the difference between the expected inflation rate (the Retail Price Index, $R P I$ ) and an exogenously given component $(x)$ which, roughly speaking, represents the expected increase of productivity the firm should attain. By making prices - at least within these periods - insensitive at the margin to firm's choices, the $R P I-x$ rule appears to eliminate the downward bias and the phenomenon known as "underinvestment". As Beesley and Littlechild (1989) put it when listing the main arguments in favor of $R P I-x$, "Because the company has the right to keep whatever profits it can earn during the specified period (and must also absorb any losses), this preserves the incentive to productive efficiency associated with unconstrained profit maximization".

${ }^{2}$ Among others, Sappington and Weisman, (1996) and Burns et al. (1998). This proposal, already debated in the UK, has also become popular among several policy makers,
} 
go beyond a pre-specified level, the $x$ factor should be automatically adjusted upwards, making the price cap more stringent; this re-distributes rents to the consumers, making the system more "fair" and more sustainable from a political viewpoint. The idea is that when this automatic mechanism is in place there is no need for discretionary interventions, as excess profits automatically trigger a tighter regulatory constraint.

However, this proposal has been criticized by some authors (see e.g., Mayer and Vickers, 1996) who - among other things - stress that if investments spur profits and therefore trigger a tighter price cap, then we have a dis-incentive to invest. The superiority of the $R P I-x$ system relative to profit sharing rules on the ground of technical efficiency was recognized also by advocates of profit sharing rules (e.g., Lyon, 1996), who only defend the PS system on the basis of overall allocative efficiency (profit sharing "typically" increases consumers surplus). Weisman (1993) shows that when price cap rules incorporate an element of profit sharing, price caps may represent a worsening relative to a pure cost based regulation (a notoriously inefficient set-up). Notice however that in practice the evidence in favour of pure price cap schemes is extremely weak; for instance, Ai and Sappington (2002) show extremely mixed results in the case of the US telecoms.

This paper tackles the issue of possible investment distortions induced by regulatory constraints and regulatory risk. While most papers in the regulation literature (e.g., Laffont and Tirole, 1986) implicitly consider fully reversible investments, we take a different approach which, following the modern theory of investment, stresses how these choices are typically irreversible. However, firms usually can choose the optimal timing of investment as well. This implies that they are endowed with an option to delay.

Our study shows that considering this aspect considerably changes the relative desirability of the aforementioned regulatory policies. Considering a continuous time model, we show that the effect of $R P I-x$ and profit sharing on the incentives to invest are identical. The reason is that the introduction of the profit ceiling into a $R P I-x$ scheme decreases the net present value of the investment, but also decreases the value of waiting (i.e., the option value) by exactly the same amount. This is an application of the "bad news principle" (Bernanke, 1983), which indicates that, under investment irreversibility, uncertainty acts asymmetrically since only the unfavorable events affect the current propensity to invest. If, thus, profit sharing (i.e., the change in the $x$ factor) occurs only in the good state, investment decisions are not affected ${ }^{3}$.

\footnotetext{
such as the Italian electricity regulator.

${ }^{3}$ In Panteghini and Scarpa (2003) we use a simple two-period model to show this first result and the distributional effectiveness of this mechanism. This is in line with the
} 
We then consider how policy uncertainty changes this result, showing that the argument according to which profit sharing - by reducing the risk of regulatory interventions due to excessive profits - encourages investment is not correct. If regulatory "surprises" are linked to profits, profit sharing is irrelevant because it protects the firm when the firm does not need to be protected, namely when profits are high. If the firm knows that the tightening of the cap may occur only in case of "good news" (high profits), its investment decisions will not be affected by this type of risk. If profit sharing has a justification, this lies in distributional considerations, not in efficiency ones.

For instance, one of the regulators' main targets is the rent extraction per se. As we have shown in Panteghini and Scarpa (2003) profit sharing has a greater ability to raise rents than price cap, and it is possible to extract the same amount of rents with a lower value of $x_{l}$. Given the amount of rents extracted from the monopolist, under profit sharing the trigger point above which investment is profitable is thus lower than under a pure price cap; in other words, investment is undertaken earlier than under the pure price cap regime.

This paper is linked to three streams of literature. The first one is the literature on investment irreversibility. Irreversibility may arise from 'lemon effects' (second-hand capital goods may be impossible to sell), and from capital specificity (see Dixit and Pindyck, 1994, and Trigeorgis, 1996) ${ }^{4}$. The irreversibility of capital expenditures is even more obvious in markets subject to price regulation, which are typically natural monopolies; the scarcity (or total absence) of firms operating in the same sector and the public constraints coming from nature of the service may represent decisive factors in this respect $^{5}$. Relative to this literature, we consider how investment is affected by different regulatory rules, showing how the option value of irreversible investments matters in determining the optimal regulatory policy.

The second stream of literature is the one on regulation and investment. From Laffont and Tirole (1986), we know that optimal price schemes entail a distortion in firms' (reversible) investment choices. The rule labelled " $R P I-$

finding of Dixit (1991) within a perfectly competitve set-up.

${ }^{4}$ Irreversibility may be caused by industry comovements as well: when a firm wants to resell its capital because of negative market conditions, but potential buyers operating in the same industry are subject to the same conditions, the firm may have to sell the capital at a lower price than otherwise possible.

${ }^{5} \mathrm{An}$ idea of the empirical relevance of irreversible investments in regulated industries can be obtained looking at the so called "stranded costs", i.e., at the value of assets that following liberalisation will hardly find a remuneration, but cannot be shifted to a different productive use. According to Lyon and Mayo (2000) these costs can be estimated for the US electricity sector "in the neighborhood of $\$ 200$ billion". 
x" (Beesley and Littlechild, 1989) was introduced exactly to counter this problem. In this case, investment does not affect price, so that this rule is supposed to have "minimum" distortionary effects on investment choices. In our paper we consider the option value of an investment of a given amount, to see how different regulatory schemes affect the timing of investment and whether regulatory risk is a good reason to introduce profit sharing. Our first result is that, even in the extremely favorable case we examine, profit sharing does not underperform the purest version of $R P I-x^{6}$. However, a second result is that profit sharing does not "beat" a pure price cap scheme in terms of ability to deal with regulatory risk. The two system seem equivalent in these respects.

Finally, an established literature indicates that political risk may a negative impact on the firms' propensity to undertake irreversible investment, and some recent contributions [see e.g. Altug et al. (2000), (2001)] have analyzed the issue with irreversibility, where the results are less clear-cut. This is in general correct, and we confirm this result in our framework. However, our main focus is to check whether the difference between the alternative regulatory regimes we consider makes a difference in this respect, and in section 3 we show that in general the introduction of profit sharing does not reduce the impact of uncertainty on investment.

The paper is organized as follows. The next section provides the analytical set-up in continuous time, stressing how profit sharing does not reduce the incentive to invest relative to a pure price cap scheme when lump-sum irreversible investments are considered. Section 3 considers regulatory risk, showing another neutrality result: profit sharing - even if it eliminates part of regulatory risk - does not outperform a pure price cap. Section 4 concludes the paper.

\section{The model}

In this section we introduce a simple continuous-time infinite horizon model describing the behavior of a firm. The market is characterized by the demand function $q(t)=q(p(t))$, where $p$ and $q$ are price and quantity of the good at time $t$. Production takes place at a per-period cost given by $C=c(t) q(t)$.

\footnotetext{
${ }^{6}$ This result can be usefully linked to some recent results of the empirical literature. For instance, Crew and Kleindorfer (1996) and the papers they review stress how the presumed superiority of optimal price rules does not emerge so clearly from experiences in different countries and sectors. The claim that $R P I-x$ rules lead to more efficient investment patterns than profit related regulatory schemes does not find a clear empirical support.
} 
Furthermore, in order to produce the firm needs to build an infrastructure:

- Assumption 1 (investment). Production requires a one-off investment of a given amount $I$.

This could be the case, for instance, of an energy distributor that has to decide whether or not to invest in a new network (either a pipeline or wires) in order to serve a town. A relevant aspect of this assumption is that the amount of investments is given ${ }^{7}$. Although firms often have the possibility to marginally adjust the value of their expenditures, it is also true that the size of most investment projects that utilities face is by and large determined by the size of the area they want to serve. Building a new electric line connecting two nodes of a transmission system to improve its reliability, or a pipeline to sell gas to a new city are choices that entail an expenditure that can only partially be controlled by the firm. This type of major investments is what we focus on ${ }^{8}$.

In these cases the firm is left with two major choices: whether or not to undertake the investment, and when to do so. Therefore, while the notion of "underinvestment" typically refers to the amount spent by the firm, in this context we will talk of underinvestment referring to the probability that a firm invests and to the date of the investment, i.e. to the present expected value of the investment. The apparent difference between our notion and the usual one is simply due to the fact that we explicitly model uncertainty and time.

If the firm does not undertake the investment, it cannot produce and its profit is zero. If the firm invests, per-period profits are ${ }^{9}$

$$
\Pi(t)=[p(t)-c(t)] q(t)
$$

The firm has an infinite time horizon and maximizes the (discounted) present value of future expected profit.

Demand is stochastic, and we introduce the following

- Assumption 2. Demand follows a geometric Brownian motion

$$
d q(t)=\alpha_{q} q(t) d t+\sigma_{q} q(t) d z_{q}
$$

\footnotetext{
${ }^{7}$ We explore the case of investment choices of endogenous size in a companion paper (Moretto, Panteghini and Scarpa, 2003).

${ }^{8}$ In Panteghini and Scarpa (2001) we show that the results below do not change if we consider cost-reducing investments.

${ }^{9}$ As we look at the consequences of different regulatory schemes on a firm's decisions, costs are considered known. The choice of the optimal price should instead consider asymmetric information, but this is beyond the scope of the current work.
} 
where $\alpha_{q}$ and $\sigma_{q}$ are the growth rate and variance parameter, respectively.

Cost follows the dynamics given by

$$
c(t)=c_{0} e^{-\gamma t}
$$

where the parameter $\gamma \geq 0$ captures possible (nominal) cost reductions over time. Price is determined by the regulator in a way we will define in the next sections.

\section{$2.1 \quad$ Pure price cap}

We will first assume that price regulation follows the traditional price cap rule known as $R P I-x$ (Beesley and Littlechild, 1989).

Definition 1 (Price cap) Under the price cap $R P I-x$ rule, if the firm starts producing at time $t^{*}$, the initial price $p_{0}$ is given, and its dynamics are defined by the difference between the inflation rate (changes in the retail price index, $R P I$ ) and an exogenous factor $x_{l}$ :

$$
p(t)=p_{0} e^{\left(R P I-x_{l}\right) t}
$$

for $t \geq t^{*}$

The factor $x=x_{l}$ is linked to the productivity gain (cost reduction) that the regulator expects the firm to be capable of achieving every year, but is determined at the beginning and is thus exogenous to the firm. As already stressed, the logic of the $R P I-x$ rule is that, by making prices insensitive at the margin to firm's choices, it appears to eliminate underinvestment. Also notice that here we assume that price dynamics is given over an infinite horizon, so that current investments have no impact on prices either in the short or in the long run.

For simplicity we assume that $[p(t)-c(t)]$ has the following dynamics ${ }^{10}$

$$
\frac{d[p(t)-c(t)]}{d t}=[p(t)-c(t)]\left(R P I-x_{l}+\gamma\right)
$$

\footnotetext{
${ }^{10}$ The assumed dynamics of $[p(t)-c(t)]$ is necessary for obtaining a closed-form solution. Equation (3) is a special case of a more general formulation obtained by assuming that price and cost evolve according to $p(t)=p_{0} e^{(R P I-x) t}$ and $c(t)=c_{0} e^{-\gamma t}$

If we use the above equations and differentiate $[p(t)-c(t)]$, we obtain

$$
\begin{aligned}
\frac{d[p(t)-c(t)]}{d t}= & \{(R P I+\gamma-x)[p(t)-c(t)]+ \\
& (R P I+\gamma-x) c(t)-\gamma[p(t)-c(t)]\}
\end{aligned}
$$
}


Using equations (1), (2), and (3), and applying Itô's lemma we can obtain the profits' dynamics

$$
d \Pi(t)=\alpha \Pi(t) d t+\sigma \Pi(t) d z
$$

where $\alpha \equiv R P I-x_{l}+\gamma+\alpha_{q}$ is the expected growth rate of per-period profits and $\sigma=\sigma_{q}$ is the standard deviation ${ }^{11}$. Given the dividend rate $\delta$ (which must be positive in order for the net value of the firm to be bounded) and the risk-free interest rate $r$, we must have $r-\delta=\alpha^{12}$. Solving for the dividend rate we thus obtain

$$
\delta(x)=r-R P I+x_{l}-\alpha_{q}-\gamma
$$

The firm must solve a standard optimal stopping time problem, namely it must choose the timing of investment to maximize the expected present value of its payoff. The problem can be represented as follows

$$
\max _{t} E\left[\left(V_{P C}(\Pi(t))-I\right) e^{-r t}\right]
$$

where $E[$.$] denotes the expectation operator, V_{P C}(\Pi(t))$ is the project value under the price cap, i.e. the $N P V$ of the project at time $t$. The solution of the problem (6), i.e. the optimal time of investments, will be defined as $t^{*}$.

Using dynamic programming, the firm's value $V_{P C}(\Pi(t))$ can be written as

$$
V_{P C}(\Pi(t))=\Pi(t) d t+e^{-r d t} E\left[V_{P C}(\Pi(t)+d \Pi(t))\right]
$$

Expanding the right-hand side and using Itô's lemma one obtains

$$
r V_{P C}(\Pi(t))=\Pi(t)+(r-\delta(x)) \Pi V_{P C_{\Pi}}(\Pi(t))+\frac{\sigma^{2}}{2} \Pi^{2} V_{P C_{\Pi \Pi}}(\Pi(t))
$$

Setting $\{(R P I+\gamma-x) c(t)-\gamma[p(t)-c(t)]\}=0$ we obtain (3). Note that the above equality implies that the mark-up is constant, i.e.

$$
\frac{p(t)-c(t)}{c(t)}=\frac{R P I+\gamma-x}{\gamma}
$$

${ }^{11}$ The model could be easily extended by assuming that $[p(t)-c(t)]$ follows a stochastic process, i.e.

$$
d[p(t)-c(t)]=[p(t)-c(t)]\left[(R P I+\gamma-x) d t+\sigma_{p c} d z_{p c}\right] .
$$

This may be the case, for instance, if the $R P I$ is a random variable and if technology shocks may take place.

${ }^{12}$ As shown in Panteghini and Scarpa (2001) considering shareholders' risk aversion does not change the result. 
where $V_{P C_{\Pi}}=\partial V_{P C} / \partial \Pi(t)$ and $V_{P C_{\Pi \Pi}}=\partial^{2} V_{P C} / \partial \Pi^{2}(t)$, respectively. For simplicity, hereafter, we will omit the time variable $t$.

To compute the value function, it is assumed that $V_{P C}(0, x)=0$, namely when $\Pi$ is very small, the project is almost worthless, and that no speculative bubbles exist ${ }^{13}$. Thus, equation (7) has the following solution

$$
V_{P C}(\Pi, x)=\frac{\Pi}{\delta\left(x_{l}\right)} \text {. }
$$

As shown by Dixit and Pindyck (1994), the option function has the following form

$$
O_{P C}(\Pi, x)=A \Pi^{\beta_{1}\left(x_{l}\right)}
$$

where $A$ is a parameter to be determined, and $\beta_{1}\left(x_{l}\right)$ is the positive root of the following characteristic equation ${ }^{14}$

$$
\frac{\sigma^{2}}{2} \beta(\beta-1)+\left(r-\delta\left(x_{l}\right)\right) \beta-r=0 .
$$

The optimal investment timing can be computed using the Value Matching Condition $(V M C)$ and the Smooth Pasting Condition $(S P C)$. Given the regulatory regime $i$ (i.e. either price cap or profit sharing), the former condition requires the net present value of the project to be equal to the option value to defer investment, $O_{i}(\Pi, x)$, namely

$$
V_{i}\left(\Pi, x_{l}\right)-I=O_{i}\left(\Pi, x_{l}\right) \text { with } i=P C, P S .
$$

The second condition requires the slopes of the functions $\left[V_{i}\left(\Pi, x_{l}\right)-I\right]$ and $O_{i}(\Pi, x)$ to match

$$
\frac{\partial\left[V_{i}\left(\Pi, x_{l}\right)-I\right]}{\partial \Pi}=\frac{\partial O_{i}\left(\Pi, x_{l}\right)}{\partial \Pi} \text { with } i=P C, P S .
$$

Conditions $V M C$ and $S P C$ characterize optimal time $t^{*}$. Notice that, given (4), this value can be associated to a profit level $\Pi^{*}$ : whenever current profit reaches $\Pi^{*}$, the firm invests.

\footnotetext{
${ }^{13}$ See Dixit and Pindyck (1994, Ch. 5 and 6).

${ }^{14}$ The positive root is

$$
\beta_{1}(x)=\frac{1}{2}-\frac{r-\delta(x)}{\sigma^{2}}+\sqrt{\left(\frac{r-\delta(x)}{\sigma^{2}}-\frac{1}{2}\right)^{2}+\frac{2 r}{\sigma^{2}}} .
$$

It is easy to ascertain that $\frac{\partial \beta_{1}(x)}{\partial x}>0$.
} 
To solve the optimal stopping time problem, let us substitute (8) and (9) into the $V M C$ and the $S P C$. We thus obtain a two-equation system with two unknowns: the trigger point of $\Pi$, above which investment is profitable, and the coefficient $A$. It is easy to show that the trigger point is ${ }^{15}$

$$
\Pi_{P C}^{*}\left(x_{l}\right) \equiv \frac{\beta_{1}\left(x_{l}\right)}{\beta_{1}\left(x_{l}\right)-1} \delta\left(x_{l}\right) I
$$

The option value multiple in equation $(10), \frac{\beta_{1}(x)}{\beta_{1}(x)-1}>1$, shows that the gross present value

$$
V_{P C}^{*}\left(\Pi_{P C}^{*}\left(x_{l}\right), x_{l}\right) \equiv \frac{\Pi_{P C}^{*}\left(x_{l}\right)}{\delta\left(x_{l}\right)}=\frac{\beta_{1}\left(x_{l}\right)}{\beta_{1}\left(x_{l}\right)-1} I
$$

must exceed the investment cost $I$ to compensate for irreversibility. It is straightforward to show that an increase in $x_{l}$ decreases both the expected profit $V_{P C}^{*}$ and the opportunity cost of investing $O_{P C}^{*}$. As shown by Moretto, Panteghini and Scarpa (2003), however, we have:

Remark 1 An increase in $x_{l}$ increases $\Pi_{P C}^{*}\left(x_{l}\right)$ (i.e., $\frac{\partial \Pi_{P C}^{*}\left(x_{l}\right)}{\partial x_{l}}>0$ ).

This implies that having a $R P I-x$ reduces the incentive to invest. Therefore, the $R P I-x$ rule is not neutral to investment decisions, a claim possibly implicit in Beesley and Littlechild (1989) but explicit in much of the policy debate.

Remark 2 We can label the above result "underinvestment" in that, given initial price and a distribution of cost parameters, the present expected value of investment is reduced because of the price cap rule.

\subsection{Profit sharing}

The $R P I-x$ rule has been criticised on the ground that cost decreases are often more substantial than predicted, and this leaves the firm most of the increase in surplus which follows privatisation.

To tackle this fairness concern in a predictable way, an alternative to $R P I-x$ has been proposed, called profit sharing ${ }^{16}$. This scheme is defined as follows:

\footnotetext{
${ }^{15}$ Substituting $\Pi_{P C}^{*}\left(x_{l}\right)$ into the system one easily obtains

$$
A=\frac{I}{\beta_{1}\left(x_{l}\right)-1}\left(\Pi_{P C}^{*}\left(x_{l}\right)\right)^{-\beta_{1}\left(x_{l}\right)}>0 .
$$

${ }^{16}$ Notice that one could also have an intervention rule based on the level of revenues instead of profits; see Sappington and Weisman (1996).
} 
Definition 2 (Profit sharing) Under the profit sharing regulatory mechanism, the RPI $-x$ rule remains in place as long as profit remains below an exogenous level $\widetilde{\Pi}$. If $\Pi(t)>\widetilde{\Pi}$, the $x$ factor immediately ${ }^{17}$ increases to $x_{h}>x_{l}$ :

$$
p(t)= \begin{cases}p_{0} e^{\left(R P I-x_{l}\right) t} & \text { if } \Pi(t) \leq \widetilde{\Pi} \\ p_{0} e^{\left(R P I-x_{h}\right) t} & \text { if } \Pi(t)>\widetilde{\Pi}, \text { with } x_{h}>x_{l}\end{cases}
$$

Thus, the price decrease factor remains constant as long as profits are considered "reasonable". When they become "excessive", this mechanism re-distributes part of the surplus to the consumers ${ }^{18}$. In this section we analyze this issue.

If $\Pi<\widetilde{\Pi}$ the Brownian motion is the same as in the previous section. Notice that it is natural to assume that the $\widetilde{\Pi}$ is above the trigger point. Otherwise, the price scheme would start from a value of $x$ already equal to $x_{h}$. This would obviously contradict the definition of profit sharing, i.e. the idea that regulation starts with a given value $x_{l}$, which is made more stringent at a later stage, in case profit goes beyond a certain level.

In this case, the Brownian motion describing the regulated payoff is

$$
d \Pi= \begin{cases}\alpha \Pi d t+\sigma \Pi d z & \text { if } \Pi(t) \leq \widetilde{\Pi} \\ \alpha^{\prime} \Pi d t+\sigma \Pi d z & \text { if } \Pi(t)>\widetilde{\Pi}\end{cases}
$$

with $\alpha^{\prime} \equiv R P I-x_{h}+\gamma+\alpha_{q}<\alpha$. If $\Pi>\widetilde{\Pi}$, therefore, the dividend rate is given by equality $r-\delta\left(x_{h}\right)=\alpha^{\prime}$, which implies the inequalities $\delta\left(x_{h}\right)>$ $\delta\left(x_{l}\right)>\delta$. When a switch point $\widetilde{\Pi}$ is introduced, both the option function and the value function must be solved separately for $\Pi<\widetilde{\Pi}$ and $\Pi>\widetilde{\Pi}$. Then, the values and derivatives of the functions are equated at the switch point $\Pi=\widetilde{\Pi}$ (see Dixit and Pindyck, 1994, pp. 186-189).

Notice that it may well happen that profit first goes beyond $\widetilde{\Pi}$, while at a later stage $\Pi<\widetilde{\Pi}$. In this case - in line with the spirit of the mechanism at stake - our formulation guarantees that the price cap goes back to its original level.

\footnotetext{
${ }^{17}$ In a discrete-time framework it would be sensible to introduce a delay between the observation of a profit level and the adjustment of the $x$ factor. In this set-up this would introduce a very substantial analytical complication with no relevant change in the results.

${ }^{18} \mathrm{It}$ would be possible to extend the current analysis to a case where different switch points $\left(\widetilde{\Pi}_{1}, \widetilde{\Pi}_{2}, \ldots\right)$ and increasing values of the $x$ factor are introduced (the equivalent of a progressive taxation).
} 
In order to check whether an investment project is profitable, both explicit and opportunity costs must be taken into account. Thus, investment is profitable if (and when) the present discounted value of future profits, net of both costs, is positive.

Following the same procedure as above, we start with the analysis of the value function. The general solution is given by the sum of a perpetual rent, with discount rate $\delta\left(x_{h}\right)$, and a homogeneous (exponential) part. Again, it is assumed that $V_{P S}\left(0, x_{l}, x_{h}\right)=0$ and that no speculative bubbles exist. Thus the solution of the value function is

$$
V_{P S}\left(\Pi, x_{l}, x_{h}\right)= \begin{cases}\frac{\Pi}{\delta\left(x_{l}\right)}+V_{1} \Pi^{\beta_{1}\left(x_{l}\right)} & \text { if } \quad \Pi<\widetilde{\Pi}, \\ \frac{\Pi}{\delta\left(x_{h}\right)}+V_{2} \Pi^{\beta_{2}\left(x_{h}\right)} & \text { if } \quad \Pi>\widetilde{\Pi} .\end{cases}
$$

As shown in Panteghini and Scarpa (2001), equating the two components of (12) at the switch point $\Pi=\widetilde{\Pi}$ and considering the $S P C$ one obtains parameters $V_{1}$ and $V_{2}$. Both parameters depend on the regulatory coefficients $x_{l}$ and $x_{h}$. In particular, $V_{1} \Pi^{\beta_{1}\left(x_{l}\right)}<0$ : this represents the present value of future profit changes due to the profit sharing (when $\Pi$ goes beyond $\widetilde{\Pi}$ ). $V_{2} \Pi^{\beta_{2}\left(x_{h}\right)}>0$ measures the present value of the future increase in the profit participation when $\Pi$ goes below $\widetilde{\Pi}$ (in fact $\partial \Pi^{\beta_{2}\left(x_{h}\right)} / \partial \Pi<0$ ).

Let us now turn to the option value, $O_{P S}\left(\Pi, x_{l}, x_{h}\right)$. In the $(0, \widetilde{\Pi})$ region, condition $O_{P S}\left(0, x_{l}, x_{h}\right)=0$ holds, and, therefore, the value function has the standard form $C_{1} \Pi^{\beta_{1}\left(x_{l}\right)}$.

In the $(\widetilde{\Pi}, \infty)$ region, instead, the option function is given by the sum of $B_{1} \Pi^{\beta_{1}\left(x_{h}\right)}$ and $B_{2} \Pi^{\beta_{2}\left(x_{h}\right)}$ (with $B_{1}$ and $B_{2}$ to be determined). $\beta_{1}\left(x_{h}\right)$ and $\beta_{2}\left(x_{h}\right)$ are the roots of the characteristic equation $\frac{\sigma^{2}}{2} \beta(\beta-1)+\left(r-\delta\left(x_{h}\right)\right) \beta-$ $r=0$, with $\beta_{1}\left(x_{h}\right)>1$ and $\beta_{2}\left(x_{h}\right)<0^{19}$. To sum up, the option function is

$$
O_{P S}\left(\Pi, x_{l}, x_{h}\right)= \begin{cases}C_{1} \Pi^{\beta_{1}\left(x_{l}\right)} & \text { if } \Pi<\widetilde{\Pi}, \\ B_{1} \Pi^{\beta_{1}\left(x_{h}\right)}+B_{2} \Pi^{\beta_{2}\left(x_{h}\right)} & \text { if } \Pi>\widetilde{\Pi} .\end{cases}
$$

By equating the values and the derivatives of the two components of the option function at point $\Pi=\widetilde{\Pi}$, we can compute $B_{1}$ and $B_{2}$ as functions of $C_{1}$. As shown in Panteghini and Scarpa (2001), $B_{1} \propto C_{1}$ and $B_{2} \propto C_{1}$.

${ }^{19}$ The roots are

$$
\beta_{1,2}\left(x^{\prime}\right)=\frac{1}{2}-\frac{r-\delta\left(x^{\prime}\right)}{\sigma^{2}} \pm \sqrt{\left(\frac{r-\delta\left(x^{\prime}\right)}{\sigma^{2}}-\frac{1}{2}\right)^{2}+\frac{2 r}{\sigma^{2}}},
$$

and it is easy to ascertain that, given derivative $\frac{\partial \beta_{1}(x)}{\partial x}>0$, inequality $\beta_{1}\left(x^{\prime}\right)>\beta_{1}(x)$ holds. 
Substituting equations (13) and (12) into the $V M C$ and $S P C$ one obtains the trigger point and the unknown parameter $C_{1}$ of the option function. In the $(0, \widetilde{\Pi})$ region, these conditions lead to the following system

$$
\begin{gathered}
\frac{\Pi}{\delta\left(x_{l}\right)}+V_{1} \Pi^{\beta_{1}\left(x_{l}\right)}-I=C_{1} \Pi^{\beta_{1}\left(x_{l}\right)} \\
\frac{1}{\delta\left(x_{l}\right)}+V_{1} \beta_{1}\left(x_{l}\right) \Pi^{\beta_{1}\left(x_{l}\right)-1}=C_{1} \beta_{1}\left(x_{l}\right) \Pi^{\beta_{1}\left(x_{l}\right)-1}
\end{gathered}
$$

which yields the same trigger point as the one obtained under the pure price cap system in equation $(10)^{20}$

$$
\Pi_{P S}^{*}\left(x_{l}\right) \equiv \frac{\beta_{1}\left(x_{l}\right)}{\beta_{1}\left(x_{l}\right)-1} \delta\left(x_{l}\right) I
$$

The equality between $\Pi_{P S}^{*}\left(x_{l}\right)$ and $\Pi_{P C}^{*}\left(x_{l}\right)$ establishes the following:

Proposition 1 (Neutrality of profit sharing) Consider a regulated monopolist which has to decide on an irreversible investment of a given amount. When demand is uncertain as modelled in (2) and the timing of investment is endogenous, correcting the RPI-x rule with a profit sharing element does not affect the timing of investment.

The neutrality (indifference) result can be explained as follows.

Since the tightening of the price cap takes place only in case of "good news", the bad news principle implies that, while profit sharing actually reduces the firm's rents, it does not interfere with its decision to invest relative to the pure price cap rule. There are no investment projects that will be undertaken under one regime, but not under the other.

The intuition for this result can be obtained considering how the option value of investment changes the firm's problem. Relative to the case of pure price cap, profit sharing reduces the net value of the project and its option value by the same amount. What matters to the decision to invest is whether or not the return from the project is positive, not "by how much"; given that profit sharing intervenes only in case profits become large enough to anyway justify the investment, this feature does not affect the firm's decision.

Another way to look at the issue is to stress that profit sharing is equivalent to equity participation by the consumers. Recall, in fact, that when

\footnotetext{
${ }^{20}$ It is easy to show that

$$
C_{1}=\frac{\beta_{2}\left(x^{\prime}\right)-1}{\beta_{1}(x)-\beta_{2}\left(x^{\prime}\right)} \frac{\delta\left(x^{\prime}\right)-\delta(x)}{\delta\left(x^{\prime}\right) \delta(x)} \widetilde{\Pi}^{1-\beta_{1}(x)}+\frac{1}{\beta_{1}(x)} \frac{\Pi_{P S}^{*}(x)^{1-\beta_{1}(x)}}{\delta(x)}>0 .
$$
}


$\Pi>\widetilde{\Pi}$, a given part of the surplus is redistributed to the consumers. When

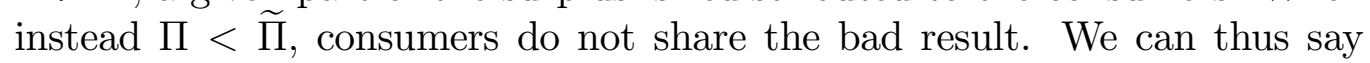
that the profit sharing device is equivalent to a case where consumers are endowed with a put option with strike price $\widetilde{\Pi}$, written on the firm's profits. If, therefore, the firm's return drops below $\widetilde{\Pi}$ (bad result), consumers sell their equity participation at zero price. Then, they will re-buy (at zero price) their participation when the firm faces a good result, namely when $\Pi>\widetilde{\Pi}$.

To clarify this point, let us concentrate on the $(0, \widetilde{\Pi})$ region (with $\Pi_{P S}^{*}\left(x_{l}\right)<$ $\widetilde{\Pi})$. Recall equations (12), (13), and the solution of $C_{1}$. The negative term $V_{1} \Pi^{\beta_{1}(x)}$ measures the value of the consumers' put option, which must be added to both the project value and the option function. This addition is necessary because, irrespective of whether the firm is waiting or producing, a worthy put option is owned by the consumers. Since $V_{1} \Pi^{\beta_{1}(x)}$ enters both functions, the difference $\left[V_{P S}\left(\Pi, x_{l}, x_{h}\right)-O_{P S}\left(\Pi, x_{l}, x_{h}\right)\right]$ is independent of the switch level $\widetilde{\Pi}$, thereby making the profit-sharing device neutral.

Easy computations show that, for a given payoff, the higher the switch point the greater the value of $V_{1}$. This implies that $\frac{\partial C_{1}}{\partial \Pi}=\frac{\partial V_{1}}{\partial \Pi}>0$. Therefore, a change in $\widetilde{\Pi}$ affects both the value and the option function by the same amount. Finally, note that the higher the switch point $\widetilde{\Pi}$ the lower the put option value $\left(-V_{1} \Pi^{\beta_{1}\left(x_{h}\right)}\right)$. Of course, for $\widetilde{\Pi} \rightarrow \infty$, profit sharing vanishes, and the value of the put option turns out to be nil.

\section{Regulatory risk}

In this section we qualify the previous neutrality result by introducing regulatory risk ${ }^{21}$. Indeed, price cap schemes are intrinsically risky for the firm, as they promise a fixed pricing rule for considerable time periods. Any policy of this kind is subject to the credibility critique: fixing price can be timeinconsistent. In particular, in order to induce the firm to invest the regulator may announce a rate of price decrease $\left(x_{l}\right)$, but may change it later. More in general, the regulator may announce a policy which "guarantees" the firm a certain profitability, and then revise this policy in various ways ${ }^{22}$. The Windfall Tax introduced in Britain in 1997 and the regulated prices freeze introduced in Italy in 2002 are examples of this phenomenon. The firm will anticipate this risk and revise its investment plans accordingly. Buckland

\footnotetext{
${ }^{21}$ In discussing tax neutrality, Sandmo (1979, p.176) argues that "academic discussions of tax reform in a world of unchanging tax rates is something of a contradiction in terms". This point well applies to regulation as well.

${ }^{22}$ Aubert and Laffont (2002) raise a similar point from a different viewpoint, analysing elements who may lead to a renegotiation of the regulatory contract.
} 
and Fraser (2001) document this fact, showing that regulatory changes are reflected by an increase in the Beta of electricity distributors in the UK, evidence that systematic political and regulatory risks are indeed present.

If we consider actual regulatory policies in the past few years, we can see that policy uncertainty (or regulatory risk) may originate from two kinds of concerns. First of all, "policy makers" ${ }^{23}$ could decide to cut prices for reasons such as inflationary concern, greater attention for low income consumers, or other reasons not directly related to a direct dissatisfaction with the outcome of the regulatory policy per se. These interventions typically interfere with the price mechanism and decrease the firm's profitability, even if the firm's profits are not the direct cause of the intervention. In other cases, policy makers may be concerned that the distribution of welfare is "unfair" in some sense, i.e. that the regulated firm is enjoying most of the benefits from the regulatory regime, while consumers keep paying high prices. In this latter case, the policy change is due to a variable which is determined endogenously in our model, i.e. profit.

In our set-up, we show that regulatory risk may or may not matter, depending on which of the above factors are at stake. To this end, it will prove useful to distinguish two types of risk. The first one is "pure" regulatory risk; by this, we mean that a positive probability exists, that Government changes, sudden inflationary concerns or other reasons external to the regulated market induce the regulator to tighten the price cap. Therefore, the possible change in the $x$ factor is not linked to any variable pertaining to the description of this market environment. The second one is profit-related risk, namely the possibility that an increase in profits might trigger an unexpected tightening of regulatory constraints.

\subsection{The effects of risk on investment decisions}

Let us start from the effects of uncertainty on the basic value of the $x$ factor, $x_{l}$. In doing so we follow Dixit's (1991) suggestion to explore the effects of regulatory uncertainty by introducing a Poisson process. On this point, we can obtain our first result ${ }^{24}$.

\footnotetext{
${ }^{23}$ We shall not distinguish between regulators and "politicians". Even if in principle the areas of competence of regulators and those of Governments are distinct, in practice this is not always the case, and it is not always relevant to the firm. On the first point, regulators are sensitive to political pressures and at times are de facto overruled by political bodies. On the second one, both regulatory interventions and legal "reforms" are able to affect firm's profitability. Given that what matters is the regulated firm's reaction, distinguishing the source of this uncertainty does not seem too relevant to our analysis.

${ }^{24}$ This is also in line with some influential articles in the taxation literature, such as Cummins et. al. (1996) and Hassett et al. (1994).
} 
Proposition 2 If, under either a price cap or a profit sharing regime, there is uncertainty about the value of the $x_{l}$ factor as

$$
d x_{l}= \begin{cases}0 & \text { with probability } 1-\lambda d t \\ \Delta x_{l} \neq 0 & \text { with probability } \lambda d t\end{cases}
$$

where $\Delta x_{l} \equiv x_{l, 1}-x_{l, 0}$, with $x_{l, 1}$ and $x_{l, 0}$ representing the price cap factor after and before the change, respectively, investment is affected by policy uncertainty. In particular, we find that:

a) if $x_{l, 0}>x_{l, 1}$, an increase in $\lambda$ encourages investment (i.e. reduces the trigger point);

b) if $x_{l, 0}<x_{l, 1}$, the effect of an increase in $\lambda$ is ambiguous;

c) the effect is the same irrespective of the regime applied.

Proof: See the Appendix.

A change in the value of $x_{l}$ affects investment. If there exists some probability that regulation gets less tight in the future, regulatory uncertanty encourages investment. The reason is that a less demanding regulatory constraint increases the NPV of the investment, and this unambiguously makes investment more desirable. In particular, notice that $x_{l}$ intervenes both in the case of good news and in the case of bad news and anything that makes "bad news" less negative encourages investment.

If there exists some probability that regulation gets tighter, the effect is ambiguous. This ambiguity is caused by the different effect of regulatory uncertainty on the value function and the option function. On the one hand, the expected increase in the $x$ factor reduces the firm's profitability, thereby discouraging investment. On the other hand, the firm might anticipate investment to exploit the lower current $x$ factor. These counteracting effects lead to an ambiguous result.

Finally, whatever the effect of this uncertainty on investment, adding a profit sharing component to the price cap does not make a difference. Notice that with profit sharing the factor $x_{l}$ is relevant only before the profit sharing threshold is reached. In this region $(\Pi \in[0, \widetilde{\Pi}])$ profit sharing does not matter. This explains point c) of Proposition 2.

Let us now consider the uncertainty that might be present even under profit sharing ${ }^{25}$, regarding the value $x_{h}$ and/or on the threshold level $\widetilde{\Pi}$. We can prove that this additional element of uncertainty does not affect a firm's investment choices.

\footnotetext{
${ }^{25}$ Notice that usually profit sharing elements are introduced exactly to reduce regulatory risk. As profit sharing entails an automatic correction in case firm's profits are "too large", regulators are better able to resist political pressures to intervene and to breach the regulatory contract.
} 
Proposition 3 Assume that, under profit sharing, the rate $x_{h}$ and the the value of $\widetilde{\Pi}$ follow Poisson processes

$$
\begin{aligned}
& d x_{h}=\left\{\begin{array}{lll}
0 & \text { with probability } & 1-\lambda d t, \\
\Delta x_{h} & \text { with probability } & \lambda d t,
\end{array}\right. \\
& d \widetilde{\Pi}=\left\{\begin{array}{lll}
0 & \text { with probability } & 1-\lambda d t, \\
\Delta \widetilde{\Pi} & \text { with probability } & \lambda d t,
\end{array}\right.
\end{aligned}
$$

where $\Delta x_{h} \equiv x_{h, 0}-x_{h, 1}$ and $\Delta \widetilde{\Pi} \equiv \widetilde{\Pi}_{0}-\widetilde{\Pi}_{1}$ with $x_{h, i}$ and $\widetilde{\Pi}_{i}$ represent the parameter values at state $i$. On condition that $\min \left(\widetilde{\Pi}_{0}, \widetilde{\Pi}_{1}\right)>\Pi_{P C}^{*}\left(x_{l}\right)$, these sources of uncertainty do not affect investment.

$\mathbf{P}$ roof. See Appendix.

The intuition for these results is straightforward, in line with the discussion of the above Proposition 2: events affecting the firm's profitability when $\Pi>\widetilde{\Pi}$ are irrelevant to investment decisions.

Finally, we can consider a case where uncertainty affects the base rate $\left(x_{l}\right)$ but conditional on the profit level: here the regulatory risk affects price regulation only after a certain (high) profit level. In order to analyze the issue, we model this "risk of expropriation" under pure price cap as follows:

$$
p(t)=\left\{\begin{array}{lll}
p_{0} e^{\left(R P I-x_{l}\right) t} & \text { if } \Pi(t) \leq \Pi^{\prime} \\
p_{0} e^{\left(R P I-x_{l}\right) t} & \text { if } \Pi(t)>\Pi^{\prime}, \text { with probability } 1-\lambda d t \\
p_{0} e^{\left(R P I-x_{h}\right) t} & \text { if } \Pi(t)>\Pi^{\prime}, \text { with probability } \lambda d t
\end{array}\right.
$$

with $\Pi^{\prime}$ exogenous. In other terms, we assume that there is a positive probability - modelled as a Poisson variable - that if the profit level is "excessive" the policy maker will intervene, making regulation tighter $\left(x_{h}>x_{l}\right)$ in order to redistribute part of the rents to the consumers. Notice that - in line with our definition of profit sharing - we assume that in case the profit level falls below $\Pi^{\prime}$ the value of the $x$ factor returns with probability 1 to its original level, $x_{l}$. For the sake of simplicity, we are also assuming that $\Pi^{\prime}$ is known and given, and the same applies to $x_{h}$.

Proposition 4 As long as $\Pi^{\prime}>\Pi_{P C}^{*}\left(x_{l}\right)$, policy uncertainty as modelled in (17) does not affect the investment decision.

The above Proposition is almost a corollary to Proposition 3. Given that uncertainty on the $x$ factor intervenes only for high profit levels, investment is not affected. 


\subsection{Discussion of the results}

In order to discuss these results, we return to our previous definition of "pure" regulatory risk and risk of rent expropriation.

The first one (totally exogenous risk) is what we have modelled in Propositions 2 and 3. These results show that uncertainty on the "base" value of the $x$ factor - the one that applies as soon as the firm operates - matters to the firm's decision. Firms may postpone or anticipate investment decisions because of policy uncertainty. Part c) of Proposition 2 is more interesting, showing that the effect of this exogenous policy uncertainty is the same, independently of the regulatory mechanism in place. This uncertainty may regard an $x$ factor which does not depend on the profit level, or may affect the value of $x$ which is supposed to change in case profits go beyond a given and known profit level - as with profit sharing, the case considered in Proposition 3; however, this does not make a difference. What matters is that the relevant $x$ factor in place was not supposed to increase in the way described by $(16)$.

Therefore, the two regimes are equivalent when the firm faces this type of exogenous uncertainty.

The second type of regulatory risk is sometimes labelled risk of expropriation (Vickers, 1993): in this case, policy changes are related to "excessive" profit levels [see (17)]. Notice that the profit sharing scheme is usually introduced exactly in order to have automatic corrections if the regulated firm's profits are excessively high, making unanticipated interventions "unnecessary".

Proposition 3 indicates that profit sharing actually neutralises the regulatory risk linked to the possibility of rent expropriation. However, the relevant point is: does a pure price cap suffer this risk? If the answer were positive, then we could conclude that profit sharing actually represents an improvement relative to a pure price cap. However, the answer - somehow surprisingly - is negative. Proposition 4 indicates that this type of risk will not interefere with investment decisions even when the regulatory regime is a pure price cap. This may be seen as a consequence of the bad news principle, which tells us that what happens in case of good news (i.e., when the profit level is higher than the one at which the firm decides to start the project) does not affect the firm's decision.

Notice that this has a relevant implication. The typical justification for profit sharing is that regulatory authorities are unable to commit not to intervene if the regulated firm's profits turn out to be very high: firms may fear that, if profits are "too high" the regulator might intervene, tightening the price cap scheme. This source of uncertainty is probably eliminated if 
the regulatory scheme envisages an automatic intervention (increasing the $x$ factor from $x_{l}$ to $x_{h}$ ). Any political pressure to expropriate the firm could find an answer in this device, thereby decreasing the incentive for the regulator to surprise the firm, and increasing the firm's incentive to invest. Our result indicates that this typical argument in favour of profit sharing is flawed: uncertainty on the level of profit after which the price cap will become tighter is irrelevant.

\section{Conclusions}

Relative to the existing literature, which implicitly assumed reversible investment by regulated firms, our results appear significantly different. While current literature indicates that profit sharing has a negative effect on investment decisions, our paper shows that this is not true. What makes a difference is the introduction of two fairly realistic assumptions: investment irreversibility and the firm's ability to decide when undertaking it. This implies that the firm is endowed with a call option to delay, which expires when investment is undertaken. We have thus shown that a profit sharing device reduces both the value of the project and the value of the option to wait by the same amount. According to the Bad News Principle, therefore, no additional distortion is introduced, with respect to price cap.

However, profit sharing as a device to foster investment by reducing a firm's uncertainty on future regulatory policies is ineffective. We have shown that uncertainty on the profit level beyond which the regulator tightens the price cap factor is not relevant to investment decisions. This is because this would occur in case profits are "too high", i.e. in the case of "good" news. This ineffectiveness of profit sharing relative to a pure price cap is simply a consequence of the Bad News Principle. Like any other source of uncertainty, political uncertainty taking place "in case of high profits" does not affect investment timing.

\section{Appendix}

This Appendix contains the proofs of Propositions 2 and 3.

\subsubsection{Proof of Proposition 2}

Define $V_{j, i}(\Pi)$ as the value function under the scheme $j=P C, P S$, either before the change $(i=0)$ or after it $(i=1)$. 
We will focus on the $(0, \widetilde{\Pi})$ region in either case. Under the pure price cap regime, by definition, we have $\widetilde{\Pi} \rightarrow \infty$. Under profit sharing, it is natural to assume that $\widetilde{\Pi}$ is above the trigger point.

Let us then compute the closed-form solutions of the value function under the new regime $(i=1)$. The solution obtained is equal to that computed in the absence of policy risk. Using dynamic programming, the firm's value $V_{j, 1}(\Pi)$ can be written as

$$
V_{j, 1}(\Pi)=\Pi d t+e^{-r d t} E\left[V_{j, 1}(\Pi+d \Pi)\right] .
$$

Expanding the right-hand side and using Itô's lemma one obtains

$$
r V_{j, 1}(\Pi)=\Pi+\left(r-\delta\left(x_{l, 1}\right)\right) \Pi \frac{\partial V_{j, 1}(\Pi)}{\partial \Pi}+\frac{\sigma^{2}}{2} \Pi^{2} \frac{\partial^{2} V_{j, 1}(\Pi)}{\partial \Pi^{2}} .
$$

Let the boundary condition $V_{j, 1}(0)=0$ hold. Thus the solution of (18) is

$$
V_{j, 1}\left(\Pi, x_{l, 1}\right)=\frac{\Pi}{\delta\left(x_{l, 1}\right)}+L_{1}^{j} \Pi^{\beta_{1}\left(x_{l, 1}\right)} \text { for } \Pi \in(0, \widetilde{\Pi})
$$

where $\beta_{1}\left(x_{l, 1}\right)$ is the positive root of the characteristic equation ${ }^{26}$

$$
\frac{\sigma^{2}}{2} \beta(\beta-1)+\left(r-\delta\left(x_{l, 1}\right)\right) \beta-r=0 .
$$

Under the assumption that no bubbles exist, as $\widetilde{\Pi} \rightarrow \infty, L_{1}^{j}$ goes to 0 . This entails that, under the pure price cap scheme, the firm's value reduces to a perpetual rent $\frac{\Pi}{\delta\left(x_{l, 1}\right)}$. Under profit sharing, instead, $L_{1}^{j} \neq 0$, since the firm's value must account for the switch in the $x$-factor which takes place whenever $\Pi>\widetilde{\Pi}$.

Let us next compute the option function

$$
O_{j, 1}(\Pi)=e^{-r d t} E\left[O_{j, 1}(\Pi+d \Pi)\right]
$$

Expanding the right-hand side and using Itô's lemma one obtains

$$
r O_{j, 1}(\Pi)=\left[r-\delta\left(x_{l, 1}\right)\right] \Pi \frac{\partial O_{j, 1}(\Pi)}{\partial \Pi}+\frac{\sigma^{2}}{2} \Pi^{2} \frac{\partial^{2} O_{j, 1}(\Pi)}{\partial \Pi^{2}}
$$

\footnotetext{
${ }^{26}$ The positive root is

$$
\beta_{1}\left(x_{l, 1}\right)=\frac{1}{2}-\frac{r-\delta\left(x_{l, 1}\right)}{\sigma^{2}}+\sqrt{\left(\frac{r-\delta\left(x_{l, 1}\right)}{\sigma^{2}}-\frac{1}{2}\right)^{2}+\frac{2 r}{\sigma^{2}}} .
$$
}


which yields

$$
O_{j, 1}(\Pi)=A_{1}^{j} \Pi^{\beta_{1}\left(x_{l, 1}\right)}
$$

where $A_{1}^{j}$ is a parameter to be determined. Using the VMC and SPC, we thus obtain the trigger point

$$
\Pi_{j}^{*}\left(x_{l, 1}\right) \equiv \Pi^{*}\left(x_{l, 1}\right) \equiv \frac{\beta_{1}\left(x_{l, 1}\right)}{\beta_{1}\left(x_{l, 1}\right)-1} \delta\left(x_{l, 1}\right) I
$$

and

$$
A_{1}^{j}-L_{1}^{j}=\frac{I}{\beta_{1}\left(x_{l, 1}\right)-1}\left[\Pi^{*}\left(x_{l, 1}\right)\right]^{-\beta_{1}\left(x_{l, 1}\right)} .
$$

Notice that under profit sharing (i.e. $L_{1}^{j} \neq 0$ ), the values of $A_{1}^{j}$ and $L_{1}^{j}$ can be computed by stitching together the two branches of the value function at point $\Pi=\widetilde{\Pi}$. However, their computation is not relevant for our purposes.

Let us now turn to the pre-change value function. Write the firm's value as

$$
V_{j, 0}(\Pi)=\Pi d t+(1-\lambda d t) e^{-r d t} E\left[V_{j, 0}(\Pi+d \Pi)\right]+\lambda d t e^{-r d t} E\left[V_{j, 1}(\Pi+d \Pi)\right] .
$$

Expanding the right-hand side and using Itô's lemma one obtains

$$
\left.(r+\lambda) V_{j, 0}(\Pi)\right)=\Pi+\left(r-\delta\left(x_{l, 0}\right)\right) \Pi \frac{\partial V_{j, 0}(\Pi)}{\partial \Pi}+\frac{\sigma^{2}}{2} \Pi^{2} \frac{\partial^{2} V_{j, 0}(\Pi)}{\partial \Pi^{2}}+\lambda V_{j, 1}(\Pi)
$$

Substituting (19) into (23) one obtains

$$
(r+\lambda) V_{j, 0}(\Pi)=\frac{\delta\left(x_{l, 1}\right)+\lambda}{\delta\left(x_{l, 1}\right)} \Pi+\lambda L_{1}^{j} \Pi^{\beta_{1}\left(x_{l, 1}\right)}+\left(r-\delta\left(x_{l, 1}\right)\right) \Pi \frac{\partial V_{j, 0}(\Pi)}{\partial \Pi}+\frac{\sigma^{2}}{2} \Pi^{2} \frac{\partial^{2} V_{j, 0}(\Pi)}{\partial \Pi^{2}}
$$

It is easy to ascertain that the general solution of $V_{j, 0}(\Pi)$ is

$$
V_{j, 0}(\Pi)=H_{0} \Pi+G_{0} \lambda L_{1}^{j} \Pi^{\beta_{1}\left(x_{l, 1}\right)}+\sum_{i=1}^{2} H_{i}^{j} \Pi^{\beta_{i}\left(x_{l 0}\right)},
$$

where

$$
H_{0} \equiv \frac{\delta\left(x_{l, 1}\right)+\lambda}{\delta\left(x_{l, 0}\right)+\lambda} \frac{1}{\delta\left(x_{l, 1}\right)}
$$




$$
G_{0} \equiv \frac{1}{r+\lambda-\beta_{1}\left(x_{l, 1}\right)\left\{\left[r-\delta\left(x_{l, 1}\right)\right]+\left[\beta_{1}\left(x_{l, 1}\right)-1\right] \frac{\sigma^{2}}{2}\right\}}
$$

and where $\beta_{i}\left(x_{l, 0}\right)$ are the roots of the characteristic equation ${ }^{27}$

$$
\frac{\sigma^{2}}{2} \beta(\beta-1)+\left(r-\delta\left(x_{l, 0}\right)\right) \beta-(r+\lambda)=0 .
$$

It is worth noting that $G_{0}$ must be positive in order for a solution to be obtained. Let the boundary condition $V_{j, 0}(0)=0$ hold. This implies that $H_{2}^{j}=0$.

Notice that, under profit sharing, $H_{1}^{P S} \neq 0$, since the firm's value must account for the switch in the $x$-factor which takes place whenever $\Pi>\widetilde{\Pi}$. Under the pure price cap scheme, instead, we have $H_{1}^{P C}=0$, on condition that no bubbles exist. Notice that the computation of $H_{1}^{P S}$ can be obtained by letting the branches of the pre-change value function meet at point $\Pi=\widetilde{\Pi}$. However, this computation is not relevant for our purposes.

Given the above conditions, the closed-form solution reduces to

$$
V_{j, 0}(\Pi)=H_{0} \Pi+G_{0} \lambda L_{1}^{j} \Pi^{\beta_{1}\left(x_{l, 1}\right)}+H_{1}^{j} \Pi^{\beta_{1}\left(x_{l, 0}\right)} .
$$

Following the same procedure, we can compute the option function. Start with the Bellman equation

$$
O_{j, 0}(\Pi)=(1-\lambda d t) e^{-r d t} E\left[O_{j, 0}(\Pi+d \Pi)\right]+\lambda d t e^{-r d t} E\left[O_{j, 1}(\Pi+d \Pi)\right] .
$$

Expanding the right-hand side and using Itô's lemma yields

$$
(r+\lambda) O_{j, 0}(\Pi)=\left(r-\delta\left(x_{l, 0}\right)\right) \Pi \frac{\partial O_{j, 0}(\Pi)}{\partial \Pi}+\frac{\sigma^{2}}{2} \Pi^{2} \frac{\partial^{2} O_{j, 0}(\Pi)(\Pi)}{\partial \Pi^{2}}+\lambda O_{j, 1}(\Pi) .
$$

Substituting (21) into (25) yields

$$
(r+\lambda) O_{j, 0}(\Pi)=\lambda A_{1}^{j} \Pi^{\beta_{1}\left(x_{l, 1}\right)}+\left(r-\delta\left(x_{l, 1}\right)\right) \Pi \frac{\partial O_{j, 0}(\Pi)}{\partial \Pi}+\frac{\sigma^{2}}{2} \Pi^{2} \frac{\partial^{2} O_{j, 0}(\Pi)}{\partial \Pi^{2}}
$$

${ }^{27}$ The positive root is

$$
\beta_{1}\left(x_{l, 0}\right)=\frac{1}{2}-\frac{r-\delta\left(x_{l, 0}\right)}{\sigma^{2}}+\sqrt{\left(\frac{r-\delta\left(x_{l, 0}\right)}{\sigma^{2}}-\frac{1}{2}\right)^{2}+\frac{2(r+\lambda)}{\sigma^{2}}} .
$$


It is easy to ascertain that the general solution of $O_{j, 0}(\Pi)$ is

$$
O_{j, 0}(\Pi)=G_{0} \lambda A_{1}^{j} \Pi^{\beta_{1}\left(x_{l, 1}\right)}+\sum_{i=1}^{2} G_{i}^{j} \Pi^{\beta_{i}\left(x_{l, 0}\right)}
$$

Using the boundary condition $O_{j, 0}(0)=0$, we have $G_{2}^{j}=0$. Thus, we obtain

$$
O_{j, 0}(\Pi)=G_{0} \lambda A_{1}^{j} \Pi^{\beta_{1}\left(x_{l, 1}\right)}+G_{1}^{j} \Pi^{\beta_{1}\left(x_{l, 0}\right)}
$$

Let us now compute the trigger point above which investment is profitable under policy risk. Substituting (24) and (26) into the VMC and SPC, we obtain a two-equation system

$$
\begin{aligned}
& H_{0} \Pi+G_{0} \lambda\left(L_{1}^{j}-A_{1}^{j}\right) \Pi^{\beta_{1}\left(x_{l, 1}\right)}+\left(H_{1}^{j}-G_{1}^{j}\right) \Pi^{\beta_{1}\left(x_{l, 0}\right)}-I=0 \\
& H_{0}-\beta_{1}\left(x_{l, 1}\right) G_{0} \lambda\left(L_{1}^{j}-A_{1}^{j}\right) \Pi^{\beta_{1}\left(x_{l, 1}\right)-1}+\beta_{1}\left(x_{l, 0}\right)\left(H_{1}^{j}-G_{1}^{j}\right) \Pi^{\beta_{1}\left(x_{l, 0}\right)-1}=0
\end{aligned}
$$

with two unknowns, i.e. the difference $\left(H_{1}^{j}-G_{1}^{j}\right)$ and the trigger point $\Pi^{*}\left(x_{0,1}\right)$. Simplifying yields

$$
\frac{\beta_{1}\left(x_{l, 0}\right)-1}{\beta_{1}\left(x_{l, 0}\right)} H_{0} \Pi_{u}+\left(1-\frac{\beta_{1}\left(x_{l, 1}\right)}{\beta_{1}\left(x_{l, 0}\right)}\right) G_{0} \lambda\left(L_{1}^{j}-A_{1}^{j}\right) \Pi_{u}^{\beta_{1}\left(x_{l, 1}\right)}=I,
$$

where $\Pi_{u}$ is the trigger point under policy uncertainty.

Let us next rewrite (27) as

$\frac{\Pi_{u}}{\Pi^{*}\left(x_{l, 0}\right)}=\left[\frac{\delta\left(x_{l, 0}\right)+\lambda}{\delta\left(x_{l, 1}\right)+\lambda} \frac{\delta\left(x_{l, 1}\right)}{\delta\left(x_{l, 0}\right)}\right]\left[\frac{I-\left(1-\frac{\beta_{1}\left(x_{l, 1}\right)}{\beta_{1}\left(x_{l, 0}\right)}\right) G_{0} \lambda\left(L_{1}^{j}-A_{1}^{j}\right) \Pi^{\beta_{1}\left(x_{l, 1}\right)}}{I}\right]$.

where $\Pi^{*}\left(x_{l, 0}\right) \equiv \frac{\beta_{1}\left(x_{l, 0}\right)}{\beta_{1}\left(x_{l, 0}\right)-1} \delta\left(x_{l, 0}\right) I$ is the trigger point in the absence of policy uncertainty when $x=x_{l, 0}$.

If $x_{l, 0}>x_{l, 1}$ we have $\frac{\delta\left(x_{l, 0}\right)+\lambda}{\delta\left(x_{l, 1}\right)+\lambda} \frac{\delta\left(x_{l, 1}\right)}{\delta\left(x_{l, 0}\right)}<1$. Moreover, the term $\left(1-\frac{\beta_{1}\left(x_{l, 1}\right)}{\beta_{1}\left(x_{l, 0}\right)}\right)$ is positive: this entails that the second term in squared brackets on the RHS is less than 1, as well. Therefore the inequality $\Pi_{u}<\Pi^{*}\left(x_{l, 0}\right)$ holds. This proves point a).

Let us finally assume $x_{l, 0}<x_{l, 1}$. In this case, we have $\frac{\delta\left(x_{l, 0}\right)+\lambda}{\delta\left(x_{l, 1}\right)+\lambda} \frac{\delta\left(x_{l, 1}\right)}{\delta\left(x_{l, 0}\right)}>1$. However, the sign of $\left(1-\frac{\beta_{1}\left(x_{l, 1}\right)}{\beta_{1}\left(x_{l, 0}\right)}\right)$ is ambiguous. Thus we have $\Pi_{u} \lessgtr \Pi^{*}\left(x_{l, 0}\right)$. This proves point $b$ ).

Finally, as can be seen, (27) is unaffected by the regulatory regime applied. Thus $\Pi_{u}$ is the trigger point irrespective of the regime implemented. This proves point c). Proposition 2 is thus proven. 


\subsubsection{Proof of Proposition 3}

Define $V_{P S, i}(\Pi)$ as the value function under the old $(i=0)$ and the new $(i=1)$ regime, respectively. We first compute the closed-form solutions of the value function and of the option function after the change. Then we turn to the pre-change case. Finally, a comparison between the two trigger points obtained is made. As will be shown, they are equal.

Start with the new regime. The solution obtained is equal to that computed in the absence of policy risk. Using dynamic programming, the firm's value $V_{P S, 1}(\Pi)$ can be written as

$$
V_{P S, 1}(\Pi)=\Pi d t+e^{-r d t} E\left[V_{P S, 1}(\Pi+d \Pi)\right] .
$$

Expanding the right-hand side and using Itô's lemma one obtains

$$
r V_{P S, 1}(\Pi)=\Pi+(r-\delta(x)) \Pi \frac{\partial V_{P S, 1}(\Pi)}{\partial \Pi}+\frac{\sigma^{2}}{2} \Pi^{2} \frac{\partial^{2} V_{P S, 1}(\Pi)}{\partial \Pi^{2}},
$$

where $x=x_{l}, x_{h, 1}$. Eq. (28) can be solved as

$$
V_{P S, 1}(\Pi)= \begin{cases}\frac{\Pi}{\delta\left(x_{l}\right)}+V_{1} \Pi^{\beta_{1}\left(x_{l}\right)} \quad \text { if } \quad \Pi<\widetilde{\Pi}_{1}, \\ \frac{\Pi}{\delta\left(x_{h, 1}\right)}+V_{2} \Pi^{\beta_{2}\left(x_{h, 1}\right)} \quad \text { if } \quad \Pi>\widetilde{\Pi}_{1} .\end{cases}
$$

Similarly, the Bellman equation of the option function is obtained

$$
O_{P S, 1}(\Pi)=e^{-r d t} E\left[O_{P S, 1}(\Pi+d \Pi)\right]
$$

Expanding the right-hand side and using Itô's lemma one obtains

$$
r O_{P S, 1}(\Pi)=(r-\delta(x)) \Pi \frac{\partial O_{P S, 1}(\Pi)}{\partial \Pi}+\frac{\sigma^{2}}{2} \Pi^{2} \frac{\partial^{2} O_{P S, 1}(\Pi)}{\partial \Pi^{2}},
$$

where $x=x_{l}, x_{h, 1}$. The equation (30) has the following solution

$$
O_{P S, 1}(\Pi, x)=\left\{\begin{array}{l}
C_{1} \Pi^{\beta_{1}\left(x_{l}\right)} \quad \text { if } \Pi<\widetilde{\Pi}_{1}, \\
B_{1} \Pi^{\beta_{1}\left(x_{h, 1}\right)}+B_{2} \Pi^{\beta_{2}\left(x_{h, 1}\right)} \quad \text { if } \quad \Pi>\widetilde{\Pi}_{1} .
\end{array}\right.
$$

Let us focus on the $\Pi \in\left(0, \widetilde{\Pi}_{1}\right)$ region. Using the VMC and SPC, we obtain the trigger point ${ }^{28}$

$$
\Pi^{*} \equiv \frac{\beta_{1}\left(x_{l}\right)}{\beta_{1}\left(x_{l}\right)-1} \delta\left(x_{l}\right) I=\Pi_{P C}^{*}\left(x_{l}\right)
$$

\footnotetext{
${ }^{28}$ See Proposition 1.
} 
and

$$
V_{1}-C_{1}=-\frac{I}{\beta_{1}\left(x_{l}\right)-1}\left[\Pi^{*}\right]^{-\beta_{1}\left(x_{l}\right)}
$$

It is easy to ascertain that $\frac{\partial\left(V_{1}-C_{1}\right)}{\partial \widetilde{\Pi}}=0$.

Let us now turn to the pre-change case. To find the trigger point above which investment is profitable, we focus on the $\Pi \in\left(0, \min \left(\widetilde{\Pi}_{0}, \widetilde{\Pi}_{1}\right)\right)$ region. This entails that both the switch levels $\widetilde{\Pi}_{0}$ and $\widetilde{\Pi}_{1}$ are sufficiently high to ensure that a tighter regulation is applied only under good states. If, otherwise, at least one of the two switch points were low the profit-sharing regulation would be implemented in the bad-news region. This would lead to a distortion.

Let us start with the firm's value. The Bellman equation is $V_{P S, 0}(\Pi)=\Pi d t+(1-\lambda d t) e^{-r d t} E\left[V_{P S, 0}(\Pi+d \Pi)\right]+\lambda d t e^{-r d t} E\left[V_{P S, 1}(\Pi+d \Pi)\right]$.

Expanding the right-hand side and using Itô's lemma one obtains

$$
(r+\lambda) V_{P S, 0}(\Pi)=\Pi+\left(r-\delta\left(x_{l}\right)\right) \Pi \frac{\partial V_{P S, 0}(\Pi)}{\partial \Pi}+\frac{\sigma^{2}}{2} \Pi^{2} \frac{\partial^{2} V_{P S, 0}(\Pi)}{\partial \Pi^{2}}+\lambda V_{P S, 1}(\Pi)
$$

Define $X(\Pi) \equiv V_{P S, 0}(\Pi)-V_{P S, 1}(\Pi)$. Subtracting (28) by (34) yields

$$
(r+\lambda) X(\Pi)=\left(r-\delta\left(x_{l}\right)\right) \Pi \frac{\partial X(\Pi)}{\partial \Pi}+\frac{\sigma^{2}}{2} \Pi^{2} \frac{\partial^{2} X(\Pi)}{\partial \Pi^{2}} .
$$

The function $X(\Pi)$ has a standard solution

$$
X(\Pi)=\sum_{i=1}^{2} X_{i} \Pi^{\beta_{i}\left(x_{l}, \lambda\right)} .
$$

$\beta_{i}\left(x_{l}, \lambda\right)$ are the roots of the characteristic equation

$$
\frac{\sigma^{2}}{2} \beta(\beta-1)+\left(r-\delta\left(x_{l}\right)\right) \beta-(r+\lambda)=0 .
$$

Given the condition $X(0)=0, X_{2}$ is nil. Using the solution of $X(\Pi)$ and equation (29) we obtain

$$
V_{P S, 0}(\Pi)=\frac{\Pi}{\delta\left(x_{l}\right)}+V_{1} \Pi^{\beta_{1}\left(x_{l}\right)}+X_{1} \Pi^{\beta_{1}\left(x_{l}, \lambda\right)},
$$


where the parameter $X_{1}$ is an unknown to be determined.

Let us next turn to the option function. The Bellman equation is

$$
O_{P S, 0}(\Pi)=(1-\lambda d t) e^{-r d t} E\left[O_{P S, 0}(\Pi+d \Pi)\right]+\lambda d t e^{-r d t} E\left[O_{P S, 1}(\Pi+d \Pi)\right] .
$$

Expanding its right-hand side and using Itô's lemma yields

$$
(r+\lambda) O_{P S, 0}(\Pi)=\left(r-\delta\left(x_{l}\right)\right) \Pi \frac{\partial O_{P S, 0}(\Pi)}{\partial \Pi}+\frac{\sigma^{2}}{2} \Pi^{2} \frac{\partial^{2} O_{P S, 0}(\Pi)}{\partial \Pi^{2}}+\lambda O_{P S, 1}(\Pi)
$$

Define $Y(\Pi) \equiv O_{P S, 0}(\Pi)-O_{P S, 1}(\Pi)$. Subtracting (30) from (36) yields

$$
(r+\lambda) Y(\Pi)=\left(r-\delta\left(x_{l}\right)\right) \Pi \frac{\partial Y(\Pi)}{\partial \Pi}+\frac{\sigma^{2}}{2} \Pi^{2} \frac{\partial^{2} Y(\Pi)}{\partial \Pi^{2}} .
$$

Given the condition $Y(0)=0, Y_{2}$ is nil. Using the solution of $Y(\Pi)$ and equation (36) we obtain the option function under regulatory risk

$$
O_{P S, 0}(\Pi)=C_{1} \Pi^{\beta_{1}\left(x_{l}\right)}+Y_{1} \Pi^{\beta_{1}\left(x_{l}, \lambda\right)},
$$

where the parameter $Y_{1}$ is an unknown to be determined.

Let us now compute the trigger point above which investment is profitable under policy risk. Substituting (35) and (37) into the (VMC) and (SPC) we obtain a two-equation system

$$
\begin{gathered}
\frac{\Pi}{\delta\left(x_{l}\right)}+\left(V_{1}-C_{1}\right) \Pi^{\beta_{1}\left(x_{l}\right)}+\left(X_{1}-Y_{1}\right) \Pi^{\beta_{1}\left(x_{l}, \lambda\right)}-I=0, \\
\frac{1}{\delta\left(x_{l}\right)}+\beta_{1}\left(x_{l}\right)\left(V_{1}-C_{1}\right) \Pi^{\beta_{1}\left(x_{l}\right)-1}+\beta_{1}\left(x_{l}, \lambda\right)\left(X_{1}-Y_{1}\right) \Pi^{\beta_{1}\left(x_{l}, \lambda\right)}=0 .
\end{gathered}
$$

Divide (39) by $\beta_{1}\left(x_{l}, \lambda\right)$ and substitute it into (38) so as to obtain

$$
\left[\frac{\beta_{1}\left(x_{l}, \lambda\right)-1}{\beta_{1}\left(x_{l}, \lambda\right)}\right] \frac{\Pi}{\delta(x)}+\left[\frac{\beta_{1}\left(x_{l}, \lambda\right)-\beta_{1}\left(x_{l}\right)}{\beta_{1}\left(x_{l}, \lambda\right)}\right]\left(V_{1}-C_{1}\right) \Pi^{\beta_{1}\left(x_{l}\right)}-I=0 .
$$

Substitute (33) into (40) and multiply it by $\frac{\beta_{1}\left(x_{l}\right)-1}{\beta_{1}\left(x_{l}\right)} \frac{1}{I}$. We thus obtain

$$
\left[\frac{\beta_{1}\left(x_{l}, \lambda\right)-1}{\beta_{1}\left(x_{l}, \lambda\right)}\right]\left(\frac{\Pi}{\Pi^{*}}\right)-\left[\frac{\beta_{1}\left(x_{l}, \lambda\right)-\beta_{1}\left(x_{l}\right)}{\beta_{1}\left(x_{l}, \lambda\right)}\right]\left(\frac{\Pi}{\Pi^{*}}\right)^{\beta_{1}\left(x_{l}\right)}-\frac{\beta_{1}\left(x_{l}\right)-1}{\beta_{1}\left(x_{l}\right)}=0 .
$$


Multiply (41) by $\frac{\beta_{1}\left(x_{l}, \lambda\right)}{\beta_{1}\left(x_{l}, \lambda\right)-1}$ so as to obtain

$$
\left(\frac{\Pi}{\Pi^{*}}\right)-\frac{\beta_{1}\left(x_{l}, \lambda\right)-\beta_{1}\left(x_{l}\right)}{\left[\beta_{1}\left(x_{l}, \lambda\right)-1\right] \beta_{1}\left(x_{l}\right)}\left(\frac{\Pi}{\Pi^{*}}\right)^{\beta_{1}\left(x_{l}\right)}-\frac{\beta_{1}\left(x_{l}, \lambda\right)\left[\beta_{1}\left(x_{l}\right)-1\right]}{\left[\beta_{1}\left(x_{l}, \lambda\right)-1\right] \beta_{1}\left(x_{l}\right)}=0 .
$$

Adding and subtracting 1 from the LHS yields

$$
\left[\left(\frac{\Pi}{\Pi^{*}}\right)-1\right]-\frac{\beta_{1}\left(x_{l}, \lambda\right)-\beta_{1}\left(x_{l}\right)}{\left[\beta_{1}\left(x_{l}, \lambda\right)-1\right] \beta_{1}\left(x_{l}\right)} \cdot\left[\left(\frac{\Pi}{\Pi^{*}}\right)^{\beta_{1}\left(x_{l}\right)}-1\right]=0 .
$$

Define $y \equiv\left(\frac{\Pi}{\Pi^{*}}\right)$ and $\phi \equiv \frac{\beta_{1}\left(x_{l}, \lambda\right)-\beta_{1}\left(x_{l}\right)}{\left[\beta_{1}\left(x_{l}, \lambda\right)-1\right] \beta_{1}\left(x_{l}\right)}<1$. Thus, eq. (42) can be rewritten as

$$
y-1=\phi\left(y^{\beta_{1}\left(x_{l}\right)}-1\right) .
$$

Equation (43) has more than one solution. We thus compute these solutions and identify the optimal one. As can be noted, solution $y=1$ holds in equation (43). This entails that $\Pi^{* *}=\Pi^{*}$. Substituting $\Pi^{*}$ into system (38)(39) one thus obtains $\left(X_{1}-Y_{1}\right)=0$. This is the first couple of solutions of system (38)-(39).

Define $y^{\prime}$ as any other solution. Given inequalities $\beta_{1}\left(x_{l}\right)>1, \phi<1$ and $\beta_{1}\left(x_{l}\right) \phi<1$, it is easy to show that any other solution is $y^{\prime}>1$. This implies that the trigger point obtained would be $\Pi^{* *}>\Pi^{*}$. Substituting this new solution into system $(38)-(39)$ yields $\left(X_{1}-Y_{1}\right)>0$. Thus $\left(\Pi^{* *}>\Pi^{*},\left(X_{1}-Y_{1}\right)>0\right)$ is the second couple of solutions. However this couple is sub-optimal. To show this, assume ab absurdo that $\left(\Pi^{* *}>\Pi^{*},\left(X_{1}-Y_{1}\right)>0\right)$ is the optimal solution. Then, using the definitions of $X(\Pi)$ and $Y(\Pi)$, we define the pre-reform project's payoff, net of both the opportunity and the effective cost, as

$$
F(\Pi) \equiv\left[V_{P S, 0}(\Pi)-O_{P S, 0}(\Pi)-I\right]
$$

Using (VMC) and eq. (44) we obtain $F\left(\Pi^{* *}\right)=0$. Rewrite (44) as

$$
F(\Pi)=\left[V_{P S, 1}(\Pi)-O_{P S, 1}(\Pi)-I\right]+\left(X_{1}-Y_{1}\right) \Pi^{\beta_{1}\left(x_{l}, \lambda\right)} .
$$

Since in $\Pi=\Pi^{*}$ the post-reform project's payoff $\left[V_{P S, 1}(\Pi)-O_{P S, 1}(\Pi)-I\right]$ is nil, we know that $F\left(\Pi^{*}\right)=\left(X_{1}-Y_{1}\right) \Pi^{* \beta_{1}\left(x_{l}, \lambda\right)}>0$. Namely, in the interval $\Pi \in\left(0, \Pi^{* *}\right)$, there exists at least one point $\left(\Pi=\Pi^{*}\right)$ such that the project's payoff is strictly positive. Thus, a rational firm facing a positive payoff in $\Pi=\Pi^{*}$, immediately invests instead of waiting until the trigger point $\Pi^{* *}$ is reached. This contradicts the assessment that $\left(\Pi^{* *}>\Pi^{*},\left(X_{1}-Y_{1}\right)>0\right)$ is the optimal solution. Therefore, the remaining solution $\left(\Pi^{* *}=\Pi^{*},\left(X_{1}-Y_{1}\right)=\right.$ $0)$ is the optimal one.

This proves Proposition 3. 


\section{References}

[1] Abel A.B. and J.C. Eberly (1996), Optimal Investment with Costly Reversibility, Review of Economic Studies, 63, iss. 4, 581-93.

[2] Abel A.B., A.K. Dixit, J.C. Eberly and R.S. Pindyck (1996), Options, the Value of Capital, and Investment, Quarterly Journal of Economics, v. 111, iss. 3, pp. 753-77.

[3] Ai, C. and D. Sappington (2002), The Impact of State Incentive Regulation on the U.S. Telecommunincations Industry, Journal of Regulatory Economics, 22, 133-60.

[4] Altug, S., F. Demers and M. Demers (2000), Political Uncertainty and Irreversible Investment: Theory and an Application to Quebec, CEPR Working Paper 2045.

[5] Altug, S., F. Demers and M. Demers (2001), The impact of Tax Risk and Persistence on Investment Decisions, Economics Bulletin, 5, 1-6.

[6] Armstrong, M., S. Cowan and J. Vickers (1995), Regulatory Reform. Economic Analysis and British Experience, MIT Press, Cambridge, Mass.

[7] Beesley, M. and S. Littlechild (1989), The Regulation of Privatized Monopolies in the United Kingdom, Rand Journal of Economics, 20, 454-72.

[8] Bernanke, B.S. (1983), Irreversibility, Uncertainty, and Cyclical Investment, Quarterly Journal of Economics, 98, 85-103.

[9] Buckland, R. and P. Fraser (2001), Political and Regulatory Risk: Beta Sensitivity in U.K. Electricity Distribution, Journal of Regulatory Economics, 19, 5-25.

[10] Burns, P., R. Turvey and T. G. Weyman-Jones (1998), The Behavior of the Firm under Alternative Regulatory Constraints, Scottish Journal of Political Economy, 45(2), 133-57

[11] Crew, M. and P. Kleindorfer (1996), Incentive Regulation in the United Kingdom and the United States: Some Lessons, Journal of Regulatory Economics, 9, 211-25.

[12] Cummins, J.G., K.A. Hassett and R.G. Hubbard (1996), Tax reforms and Investment: A Cross-Country Comparison, Journal of Public Economics, (62)1-2, pp. 237-273. 
[13] Dixit, A. (1991), Irreversible Investment with Price Ceilings, Journal of Political Economy, 99, 541-57.

[14] Dixit, A. and Pindyck R.S. (1994), Investment under Uncertainty, Princeton University Press.

[15] Hassett, K.A. and G.E. Metcalf (1994), Investment with Uncertain Tax Policy: Does Random Tax Policy Discourage Investment?, NBER W.P. 4780, June.

[16] Karlin S. and H.M. Taylor (1975), A First Course in Stochastic Processes, New York, Academic Press.

[17] Laffont, J. J. and J. Tirole (1986), Using Cost Observations to Regulate Firms, Journal of Political Economy, vol.94, 614-41.

[18] Lyon, T. (1996), A Model of Sliding-Scale Regulation, Journal of Regulatory Economics, 9, 227-47.

[19] Lyon, T. and J. Mayo (2000), Regulatory Opportunism and Investment behavior: Evidence from the U.S. Electricity Utility Industry, Indiana University Discussion Paper.

[20] Mayer, C. and J. Vickers (1996), Profit-Sharing Regulation: An Economic Appraisal, Fiscal Studies, 17, 1-18.

[21] Moretto, M., P. M. Panteghini and C. Scarpa (2003), Regulation and Irreversible Investments of Endogenous Size, mimeo, University of Brescia.

[22] Panteghini, P. M. and C. Scarpa (2001), Incentives to (Irreversible) Investments under Different Regulatory Regimes, CES-ifo Working Paper No. 417.

[23] Panteghini, P. M. and C. Scarpa (2003), The distributional efficiency of alternative regulatory regimes: a real option approach, International Tax and Public Finance, forthcoming.

[24] Sandmo, A. (1979), A Note on the Neutrality of the Cash Flow Corporation Tax, Economics Letters, 4, pp. 173-6.

[25] Sappington, D. and D. Weisman (1996), Revenue Sharing in Incentive Regulation Plans, Information Economics and Policy, 8, 229-48. 
[26] Trigeorgis, L. (1996), Real Options, Managerial Flexibility and Strategy in Resource Allocation, MIT Press, Cambridge, Mass..

[27] Vickers, J. (1993) Privatization and the Risk of Expropriation, in M. Baldassarri, L. Paganetto and E. Phelps, eds. Privatization Processes in Eastern Europe, Macmillan, London

[28] Weisman, D. (1993), Superior Regulatory Regimes in Theory and in Practice, Journal of Regulatory Economics, 5, 355-66. 


\title{
CESifo Working Paper Series
}

\author{
(for full list see www.cesifo.de)
}

866 Ernst Fehr, Urs Fischbacher, Bernhard von Rosenbladt, Jürgen Schupp, and Gert G. Wagner, A Nation-Wide Laboratory. Examining Trust and Trustworthiness by Integrating Behavioral Experiments into Representative Survey, February 2003

867 Frank Heinemann, The Inflationary Impact of Wage Indexation, February 2003

868 Eytan Sheshinski, Bounded Rationality and Socially Optimal Limits on Choice in a Self-Selection Model, February 2003

869 M. Hashem Pesaran, Estimation and Inference in Large Heterogenous Panels with Cross Section Dependence, February 2003

870 Luis H. R. Alvarez and Erkki Koskela, On the Tree-Cutting Problem under Interest Rate and Forest Value Uncertainty, February 2003

871 Norbert Berthold and Rainer Fehn, Unemployment in Germany: Reasons and Remedies, February 2003

872 Clemens Fuest, Bernd Huber, and Philipp Tilleßen, Tax Policy and Entrepreneurship in the Presence of Asymmetric Information in Capital Markets, February 2003

873 Eytan Sheshinski, Optimum and Risk-Class Pricing of Annuities, February 2003

874 Willi Leibfritz, Paul O'Brien and Jean-Christophe Dumont, Effects of Immigration on Labour Markets and Government Budgets - An Overview, February 2003

875 M. Hashem Pesaran and Allan Timmermann, How Costly is it to Ignore Breaks when Forecasting the Direction of a Time Series?, February 2003

876 Thorvaldur Gylfason and Gylfi Zoega, Education, Social Equality and Economic Growth: A View of the Landscape, February 2003

877 Robin Boadway and Jean-François Tremblay, Public Economics and Startup Entrepreneurs, February 2003

878 Erkki Koskela and Roope Uusitalo, The Un-Intended Convergence: How the Finnish Unemployment Reached the European Level, February 2003

879 Robert Fenge and Volker Meier, Pensions and Fertility Incentives, February 2003

880 Eytan Sheshinski, Note on Income Taxation and Occupational Choice, February 2003

881 A B Atkinson, Income Inequality in OECD Countries: Data and Explanations, February 2003 
882 Thomas Gehrig and Rune Stenbacka, Venture Cycles: Theory and Evidence, February 2003

883 Ralf Becker and Thomas Hellmann, The Genesis of Venture Capital - Lessons from the German Experience, March 2003

884 Eytan Sheshinski, Note on the Optimum Pricing of Annuities, March 2003

885 Paul De Grauwe and Magdalena Polan, Globalisation and Social Spending, March 2003

886 F. van der Ploeg, Do Social Policies Harm Employment and Growth?, March 2003

887 Mirjam van Praag, Initial Capital Constraints Hinder Entrepreneurial Venture Performance: An empirical analysis, March 2003

888 Bernard Steunenberg, Coordinating Sectoral Policymaking: Searching for Countervailing Mechanisms in the EU Legislative Process, March 2003

889 Eytan Sheshinski, Optimum Delayed Retirement Credit, March 2003

890 Frederick van der Ploeg, Rolling Back the Public Sector - Differential effects on employment, investment and growth, March 2003

891 Paul De Grauwe and Marc-Alexandre Sénégas, Monetary Policy in EMU when the Transmission is Asymmetric and Uncertain, March 2003

892 Steffen Huck and Kai A. Konrad, Strategic Trade Policy and the Home Bias in Firm Ownership Structure, March 2003

893 Harry Flam, Turkey and the EU: Politics and Economics of Accession, March 2003

894 Mathias Hoffmann and Ronald MacDonald, A Re-examination of the Link between Real Exchange Rates and Real Interest Rate Differentials, March 2003

895 Badi H. Baltagi, Espen Bratberg, and Tor Helge Holmås, A Panel Data Study of Physicians' Labor Supply: The Case of Norway, March 2003

896 Dennis C. Mueller, Rights and Citizenship in the European Union, March 2003

897 Jeremy Edwards, Gains from Trade in Tax Revenue and the Efficiency Case for Trade Taxes, March 2003

898 Rainer Fehn and Thomas Fuchs, Capital Market Institutions and Venture Capital: Do They Affect Unemployment and Labour Demand?, March 2003

899 Ronald MacDonald and Cezary Wójcik, Catching Up: The Role of Demand, Supply and Regulated Price Effects on the Real Exchange Rates of Four Accession Countries, March 2003 
900 R. Selten, M. Schreckenberg, T. Pitz, T. Chmura, and S. Kube, Experiments and Simulations on Day-to-Day Route Choice-Behaviour, April 2003

901 Stergios Skaperdas, Restraining the Genuine Homo Economicus: Why the Economy Cannot be Divorced from its Governance, April 2003

902 Yin-Wong Cheung, Menzie D. Chinn, and Antonio Garcia Pascual, What Do We Know about Recent Exchange Rate Models? In-Sample Fit and Out-of-Sample Performance Evaluated, April 2003

903 Mika Widgrén, Enlargements and the Principles of Designing EU - Decision-Making Procedures, April 2003

904 Phornchanok Cumperayot, Dusting off the Perception of Risk and Returns in FOREX Markets, April 2003

905 Kai A Konrad, Inverse Campaigning, April 2003

906 Lars P. Feld and Stefan Voigt, Economic Growth and Judicial Independence: Cross Country Evidence Using a New Set of Indicators, April 2003

907 Giuseppe Bertola and Pietro Garibaldi, The Structure and History of Italian Unemployment, April 2003

908 Robert A.J. Dur and Otto H. Swank, Producing and Manipulating Information, April 2003

909 Christian Gollier, Collective Risk-Taking Decisions with Heterogeneous Beliefs, April 2003

910 Alexander F Wagner, Mathias Dufour, and Friedrich Schneider, Satisfaction not Guaranteed - Institutions and Satisfaction with Democracy in Western Europe, April 2003

911 Ngo Van Long, Raymond Riezman, and Antoine Soubeyran, Trade, Wage Gaps, and Specific Human Capital Accumulation, April 2003

912 Andrea Goldstein, Privatization in Italy 1993-2002: Goals, Institutions, Outcomes, and Outstanding Issues, April 2003

913 Rajshri Jayaraman and Mandar Oak, The Signaling Role of Municipal Currencies in Local Development, April 2003

914 Volker Grossmann, Managerial Job Assignment and Imperfect Competition in Asymmetric Equilibrium, April 2003

915 Christian Gollier and Richard Zeckhauser, Collective Investment Decision Making with Heterogeneous Time Preferences, April 2003

916 Thomas Moutos and William Scarth, Some Macroeconomic Consequences of Basic Income and Employment Subsidies, April 2003 
917 Jan C. van Ours, Has the Dutch Miracle Come to an End?, April 2003

918 Bertil Holmlund, The Rise and Fall of Swedish Unemployment, April 2003

919 Bernd Huber and Marco Runkel, Optimal Design of Intergovernmental Grants under Asymmetric Information, April 2003

920 Klaus Wälde, Endogenous Business Cycles and Growth, April 2003

921 Ramon Castillo and Stergios Skaperdas, All in the Family or Public? Law and Appropriative Costs as Determinants of Ownership Structure, April 2003

922 Peter Fredriksson and Bertil Holmlund, Improving Incentives in Unemployment Insurance: A Review of Recent Research, April 2003

923 Bernard M.S. van Praag and Adam S. Booij, Risk Aversion and the Subjective Time Discount Rate: A Joint Approach, April 2003

924 Yin-Wong Cheung, Dissecting the PPP Puzzle: The Unconventional Roles of Nominal Exchange Rate and Price Adjustment, April 2003

925 Ugo Trivellato and Anna Giraldo, Assessing the 'Choosiness' of Job Seekers. An Exploratory Approach and Evidence for Italy, April 2003

926 Rudi Dornbusch and Stanley Fischer, International Financial Crises, April 2003

927 David-Jan Jansen and Jakob de Haan, Statements of ECB Officials and their Effect on the Level and Volatility of the Euro-Dollar Exchange Rate, April 2003

928 Mario Jametti and Thomas von Ungern-Sternberg, Assessing the Efficiency of an Insurance Provider - A Measurement Error Approach, April 2003

929 Paolo M. Panteghini and Guttorm Schjelderup, Competing for Foreign Direct Investments: A Real Options Approach, April 2003

930 Ansgar Belke, Rainer Fehn, and Neil Foster, Does Venture Capital Investment Spur Employment Growth?, April 2003

931 Assar Lindbeck, Sten Nyberg, and Jörgen W. Weibull, Social Norms and Welfare State Dynamics, April 2003

932 Myrna Wooders and Ben Zissimos, Hotelling Tax Competition, April 2003

933 Torben M. Andersen, From Excess to Shortage - Recent Developments in the Danish Labour Market, April 2003

934 Paolo M. Panteghini and Carlo Scarpa, Irreversible Investments and Regulatory Risk, April 2003 